\title{
\begin{tabular}{l|l} 
Mibraries & DSpace@MIT
\end{tabular}
}

\author{
MIT Open Access Articles
}

\section{Oxidative Addition Complexes as Precatalysts for Cross-Coupling Reactions Requiring Extremely Bulky Biarylphosphine Ligands}

The MIT Faculty has made this article openly available. Please share how this access benefits you. Your story matters.

Citation: Ingoglia, Bryan T. and Stephen L. Buchwald. “Oxidative Addition Complexes as Precatalysts for Cross-Coupling Reactions Requiring Extremely Bulky Biarylphosphine Ligands." Organic Letters 19, 11 (May 2017): 2853-2856 (C) 2017 American Chemical Society

As Published: http://dx.doi.org/10.1021/ACS.ORGLETT.7B01082

Publisher: American Chemical Society (ACS)

Persistent URL: http://hdl.handle.net/1721.1/116337

Version: Author's final manuscript: final author's manuscript post peer review, without publisher's formatting or copy editing

Terms of Use: Article is made available in accordance with the publisher's policy and may be subject to US copyright law. Please refer to the publisher's site for terms of use. 
Org Lett. 2017 June 02; 19(11): 2853-2856. doi:10.1021/acs.orglett.7b01082.

\title{
Oxidative Addition Complexes as Precatalysts for Cross- Coupling Reactions Requiring Extremely Bulky Biarylphosphine Ligands
}

\author{
Bryan T. Ingoglia and Stephen L. Buchwald \\ Department of Chemistry, Massachusetts Institute of Technology, Cambridge, Massachusetts \\ 02139, United States
}

\begin{abstract}
In this report, we describe the application of palladium-based oxidative addition complexes (OACs) as effective precatalysts for $\mathrm{C}-\mathrm{N}, \mathrm{C}-\mathrm{O}$, and $\mathrm{C}-\mathrm{F}$ cross-coupling reactions with a variety of (hetero)arenes. These complexes offer a convenient alternative to previously developed classes of precatalysts, particularly in the case of the bulkiest biarylphosphine ligands, for which palladacycle-based precatalysts do not readily form. The precatalysts described herein are easily prepared and stable to long term storage under air.
\end{abstract}

\section{Graphical Abstract}

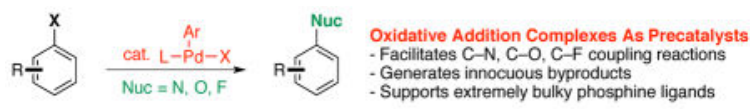

The use of biarylphosphines as supporting ligands in palladium catalysis has played an important role in the development of synthetic methods that can be used to form $\mathrm{C}-\mathrm{C},{ }^{1} \mathrm{C}-$ $\mathrm{N},{ }^{2} \mathrm{C}-\mathrm{O},{ }^{3}$ and $\mathrm{C}-\mathrm{F}^{4}$ bonds in a wide variety of settings. To facilitate the use of these ligands, we have developed several generations of palladacyclic precatalysts (G1-G5, Figure 1), which are able to accommodate a range of phosphine-based ligands. ${ }^{5,6}$ These precatalysts can be used to promote cross-coupling reactions with high efficiency. This is due, in part, to the preassociation of the ligand with the Pd center and to the rapid formation of a $\mathrm{L}-\mathrm{Pd}(0)$ species under the reaction conditions. In addition, these $\mathrm{Pd}(\mathrm{II})$ precatalysts are easily handled and stable to long-term storage without the need to carefully exclude air or water.

\footnotetext{
${ }^{\star}$ Corresponding Author: sbuchwal@mit.edu.

Notes

The authors declare the following competing financial interest(s): MIT has patents on some of the ligands and precatalysts described in this work from which S.L.B. as well as former or current coworkers receive royalty payments.

Supporting Information

The Supporting Information is available free of charge on the ACS Publications website.

Experimental procedures and characterization data for new compounds. (PDF)

Crystal data of P2 (CIF)
} 
Biarylphosphine ligands bearing bis(tert-butyl) and bis(1-adamantyl) phosphino groups (e.g., L1-L4) are useful supporting ligands for catalysts that promote $\mathrm{C}-\mathrm{O}$ and $\mathrm{C}-\mathrm{F}$ crosscoupling reactions. ${ }^{7}$ Among other things, these ligands are believed to facilitate the challenging reductive elimination steps of these processes. ${ }^{3 c, 4}$ Methods to prepare palladacycle precatalysts based on these particularly bulky ligands are less successful than with other ligands. While $\mathbf{G 3}$ precatalysts containing these ligands are readily isolated, they form carbazole upon catalyst activation, which occasionally can cause inhibition of the catalyst based on kinetic and mechanistic studies. ${ }^{5 c, 6 a, 8}$ Precatalysts of type $\mathbf{G 4}$ and $\mathbf{G 5}$ were prepared to address this, among other issues. However, G4 and G5-based precatalysts based on L1-L4 are only formed with difficulty. ${ }^{5 \mathrm{~d}}$

As an alternative, our group has developed $[\mathrm{L}-\mathrm{Pd}]_{2}(\mathrm{cod})(\operatorname{cod}=1,5$-cyclooctadiene $)$ precatalysts (Figure 1) which are suitable for $\mathbf{L 1}-\mathbf{L} 4 .{ }^{9}$ However, not all biarylphosphine ligands form precatalysts of this type. Furthermore, these complexes are generally air sensitive and exhibit poor solubility in organic solvents, making them less convenient to handle. ${ }^{4 a, 9,10}$ Thus we set out to find alternative Pd(II) precatalysts that would overcome these issues.

We hypothesized that a potential solution would be to use oxidative addition complexes (OACs) of general formula $\mathrm{L}-\mathrm{Pd}(\mathrm{Ar}) \mathrm{X}$ as precatalysts. These are readily obtained by oxidative addition of aryl (pseudo)halides to an in situ generated L-Pd(0) species. Moreover, since they serve as presumptive intermediates on the catalytic cycle for cross-coupling processes, these OACs should be competent palladium sources for a variety of $\mathrm{C}-\mathrm{X}$ bondforming reactions. ${ }^{11,12}$

We were particularly interested in the use of OACs for the development of a simplified and improved protocol for the palladium-catalyzed fluorination of aryl (pseudo)halides. Previously, L1 (AlPhos) was found to be an effective supporting ligand for the palladiumcatalyzed fluorination of a broad range of aryl bromides and triflates. ${ }^{4}$ However, preliminary investigation into the use of palladacycle precatalysts yielded poor outcomes, likely due to the formation of inhibiting byproducts (e.g., HF or carbazole) during catalyst activation, as well as the inefficiency of catalyst activation itself in the absence of a suitable exogenous base. ${ }^{4 \mathrm{c}}$ We expected OACs to address both of these issues as no base is needed for activation, while the only byproduct is simply another aryl fluoride, which is presumably innocuous.

To test this hypothesis, precatalysts $\mathbf{P 1 - P 3}$ were prepared by combining the biarylphosphine ligand, aryl bromide or triflate, and ( $\mathrm{cod}) \mathrm{Pd}\left(\mathrm{CH}_{2} \mathrm{TMS}\right)_{2}{ }_{2}$ in pentane, from which the desired complex precipitated. Filtering and washing the precipitate afforded the pure complexes in moderate to good isolated yield, while remaining free ligand may be recovered from the filtrate (Scheme I, see Supporting Information (SI) for details). 4-Trifluoromethylphenyl was selected as the aryl group for $\mathbf{P 1}$ and $\mathbf{P 2}$, since catalyst activation via the formation of 4fluorobenzotrifluoride under the reaction conditions was expected to be facile. Moreover, this byproduct was expected to be inert under the reaction conditions and readily removed due to its volatility. The structures of $\mathbf{P 1}$ and $\mathbf{P 2}$ were confirmed by NMR spectroscopy as well as by X-ray crystallography in the case of $\mathbf{P} \mathbf{2}$, providing the first crystal structure of a 
complex derived from an aryl triflate with $\mathbf{L} \mathbf{1}$ as the supporting ligand (Figure 1). The complexes are stable under air in a bench-top desiccator in the solid state for at least 10 months, as judged by ${ }^{31} \mathrm{P}$ NMR spectroscopy. ${ }^{13}$

Our reported conditions for the palladium-catalyzed fluorination of aryl bromides and triflates call for $[\mathbf{L 1}-\mathrm{Pd}]_{2}(\mathrm{cod})$ as the source of ligand and palladium. ${ }^{\text {aa }}$ We initially employed P1 alone in place of the cyclooctadiene complex for the fluorination of 1bromo-4- $n$-butylbenzene and found that it performed poorly compared to the previously developed conditions (Table 1, entries 1 vs. 2). However, when exogenous cyclooctadiene was added, the yield increased substantially (Table 1 , entry 3 ). We postulate this additive may improve the yield by stabilizing any off-cycle $\operatorname{Pd}(0)$ species and averting irreversible catalyst deactivation. Encouraged by this result, we examined the generality of these conditions toward the fluorination of aryl triflates. Indeed, P1 also served as a competent precatalyst for the fluorination of aryl triflates, although small amounts of the corresponding aryl bromides were also formed, complicating isolation of the desired products. To address this issue, we prepared triflate analogue P2. For aryl triflate substrates, this precatalyst exhibits the same catalytic activity as $\mathbf{P 1}$, while avoiding the formation of aryl bromide side products. However, $\mathbf{P 2}$ does not efficiently transform aryl bromides into aryl fluorides, perhaps due to inefficient activation of the precatalyst by the fluoride sources present under the reaction conditions. Thus, we employed $\mathbf{P 1}$ and $\mathbf{P 2}$ for the fluorination of aryl bromides and triflates, respectively. To gain a sense of the generality of these new protocols, a small collection of substrates were examined under these conditions. Substrates containing potentially sensitive functional groups, including an internal alkyne (2a), an aldehyde (2c), and an azo (2f) were fluorinated in good to excellent yield, with a regioisomeric side product observed only in the case of $\mathbf{2 e}$ (Scheme 2). ${ }^{14}$

After investigating OAC precatalysts in the context of $\mathrm{C}-\mathrm{F}$ bond-forming reactions, we explored the applicability of this method to other bond-forming processes. To facilitate purification of the cross coupling product, we considered precatalysts which would produce easily removed byproducts upon activation. In particular, we designed an OAC bearing a trimethylsilyl ethyl (TMSE) ester, which can be selectively cleaved with fluoride to liberate the corresponding carboxylate, which is easier to separate from the desired product. Based on previously reported $\mathrm{C}-\mathrm{O}$ and $\mathrm{C}-\mathrm{N}$ cross-coupling processes, ${ }^{3,15} \mathbf{L 2}$ ( $t$-BuBrettPhos) was selected as the ligand for the precatalyst. Complex $\mathbf{P 3}$ was therefore prepared as a precatalyst for these types of coupling reactions. The new precatalyst was first employed for the $N$-arylation of amino acid esters under mild and stereoretentive conditions. By employing P3, the desired arylation products were formed in moderate to good yields with high levels of enantioretention (Scheme 3). Treatment with TBAF, if necessary, was mild enough to cleave the aminated TMSE ester present in the byproduct selectively, simplifying purification of the desired product $(\mathbf{3 b}, \mathbf{3 d})$ without eroding the enantiomeric excess and with merely one percent or less of the byproduct as judged by the ${ }^{1} \mathrm{H}$ NMR spectrum after chromatographic purification (see SI for details). Other compounds (3a, 3c) could be purified without the addition of fluoride. Precatalyst $\mathbf{P 3}$ was also found to be suitable for the cross-coupling of oxygen nucleophiles (Scheme 4). Heterocyclic aryl halides, including a quinoxaline (4a), an indazole (4b), and an isoquinoline (4d), were hydroxylated or 
methoxylated in good yield. An $N$-benzyl dibromophenothiazine (4c) readily underwent coupling to afford the bis(methoxylation) product in excellent yield.

In summary, we have demonstrated that oxidative addition complexes based on palladium, supported by extremely bulky dialkylbiaryl phosphine ligands, can serve as active precatalysts for a wide variety of challenging, synthetically useful carbon-heteroatom bondforming reactions. The complexes are well-characterized, easily handled outside of a glovebox, and provide a means of introducing $\mathrm{L}-\mathrm{Pd}(0)$ into a reaction without the formation of potentially inhibitory byproducts.

\section{Supplementary Material}

Refer to Web version on PubMed Central for supplementary material.

\section{Acknowledgments}

We thank Aldrich for a gift of $t$-BuBrettPhos (L2). We thank Dr. Mycah Uehling (MIT), Dr. Nicholas White (MIT), and Dr. Yiming Wang (MIT) for assistance in the preparation of this manuscript. We thank Dr. Aaron Sather (MIT), Dr. Sandra King (MIT), and Anni Zhang (MIT) for providing aryl triflate starting materials for the project. We thank Dr. Kurt Armbrust (MIT) and Dr. Pedro Arrechea (MIT) for helpful discussions. We thank Jonathan Becker (MIT) for solving the X-ray structure of $\mathbf{P 2}$. The X-ray diffractometer was purchased with the help of funding from the National Science Foundation (Grant No. CHE 0946721). The Varian $500 \mathrm{MHz}$ instrument used for portions of this work was supported by the National Science Foundation (Grant No. CHE 9808061). Research reported in this publication was supported by the National Institutes of Health under award number GM46059 and GM58160. The content is solely the responsibility of the authors and does not necessarily represent the official views of the National Institutes of Health.

\section{References}

1. (a) Han C, Buchwald SL. J Am Chem Soc. 2009; 131:7532-7533. [PubMed: 19441851] (b) Yang Y, Oldenhuis NJ, Buchwald SL. Angew Chem Int Ed. 2013; 52:615-619.(c) Martin R, Buchwald SL. Acc Chem Res. 2008; 41:1461-1473. [PubMed: 18620434]

2. Ruiz-Castillo P, Buchwald SL. Chem Rev. 2016; 116:12564-12649. [PubMed: 27689804]

3. (a) Cheung CW, Buchwald SL. Org Lett. 2013; 15:3998-4001. [PubMed: 23883393] (b) Cheung CW, Buchwald SL. J Org Chem. 2014; 79:5351-5358. [PubMed: 24762125] (c) Wu X, Fors BP, Buchwald SL. Angew Chem Int Ed. 2011; 50:9943-9947.

4. (a) Sather AC, Lee HG, De La Rosa VY, Yang Y, Müller P, Buchwald SL. J Am Chem Soc. 2015; 137:13433-13438. [PubMed: 26413908] (b) Sather AC, Buchwald SL. Acc Chem Res. 2016; 49:2146-2157. [PubMed: 27656765] (c) Watson DA, Su M, Teverovskiy G, Zhang Y, GarcíaFortanet J, Kinzel T, Buchwald SL. Science. 2009; 325:1661-1664. [PubMed: 19679769] (d) Milner PJ, Kinzel T, Zhang Y, Buchwald SL. J Am Chem Soc. 2014; 136:15757-15766. [PubMed: 25299957]

5. (a) Biscoe MR, Fors BP, Buchwald SL. J Am Chem Soc. 2008; 130:6686-6687. [PubMed: 18447360] (b) Bruno NC, Tudge MC, Buchwald SL. Chem Sci. 2013; 4:916-920. [PubMed: 23667737] (c) Bruno NC, Buchwald SL. Org Lett. 2013; 15:2876-2879. [PubMed: 23675976] (d) Bruno NC, Niljianskul N, Buchwald SL. J Org Chem. 2014; 79:4161-4166. [PubMed: 24724692]

6 . For a class of precatalysts based on $\pi$-allyl and indenyl complexes, which have been shown to accommodate very bulky biarylphosphines, see: DeAngelis AJ, Gildner PG, Chow R, Colacot TJ. J Org Chem. 2015; 80:6794-6813. [PubMed: 26035637] Melvin PR, Nova A, Balcells D, Dai W, Hazari N, Hruszkewycz DP, Shah HP, Tudge MT. ACS Catal. 2015; 5:3680-3668.

7. (a) Lundgren RJ, Stradiotto M. Chem Eur J. 2012; 18:9758-9759. [PubMed: 22786694] (b) Bariwal J, Van der Eycken EV. Chem Soc Rev. 2013; 42:9283-9303. [PubMed: 24077333] (c) DeAngelis, A., Colacot, TJ. In New Trends in Cross-Coupling: Theory and Applications. Colacot, TJ., editor. RSC; Cambridge, U.K: 2015. p. 20-90.(d) Seechurn, CCC., Li, H., Colacot, TJ. In New Trends in 
Cross-coupling: Theory and Applications. Colacot, TJ., editor. RSC; Cambridge, U.K: 2015. p. 91-138.

8. Park NH, Vinogradova EV, Surry DS, Buchwald SL. Angew Chem Int Ed. 2015; 54:8259-8262.

9. Lee HG, Milner PJ, Colvin MT, Andreas L, Buchwald SL. Inorg Chim Acta. 2014; 422:188-192.

10. For a capsule-based strategy to enable convenient handling of $[\mathrm{L}-\mathrm{Pd}]_{2}(\mathrm{cod})$ complexes in combination with hygroscopic bases, see: Sather AC, Lee HG, Colombe JR, Zhang A, Buchwald SL. Nature. 2015; 524:208-211. [PubMed: 26268191]

11. In fact, OACs have found use in the context of mechanistic experiments, see: Moser WR, Wang AW, Kildahl NK. J Am Chem Soc. 1988; 110:2816-2820.Wallow TI, Goodson FE, Novak BM. Organometallics. 1996; 15:3708-3716. Verbeeck S, Meyers C, Franck P, Jutand A, Maes BUW. Chem Eur J. 2010; 16:12831-12837. [PubMed: 20967805]

12. For examples of a complex with formula $\left(\mathrm{Ph}_{3} \mathrm{P}\right)_{2} \mathrm{Pd}(\mathrm{Ph}) \mathrm{I}$ catalyzing a $\mathrm{C}-\mathrm{C}$ coupling, see: Fauvarque JF, Jutand A. J Organomet Chem. 1979; 177:273-281.Sekiya A, Ishikawa N. J Organomet Chem. 1976; 118:349-354.

13. Complex P1 slowly reacts in solution with oxygen, but is stable in the solid state.

14. Formation of regioisomeric products occurs with certain types of substrates in the Pd-catalyzed fluorination reaction. $4 \mathrm{~d}$

15. King SM, Buchwald SL. Org Lett. 2016; 18:4128-4131. [PubMed: 27498618]

Org Lett. Author manuscript; available in PMC 2017 September 01. 

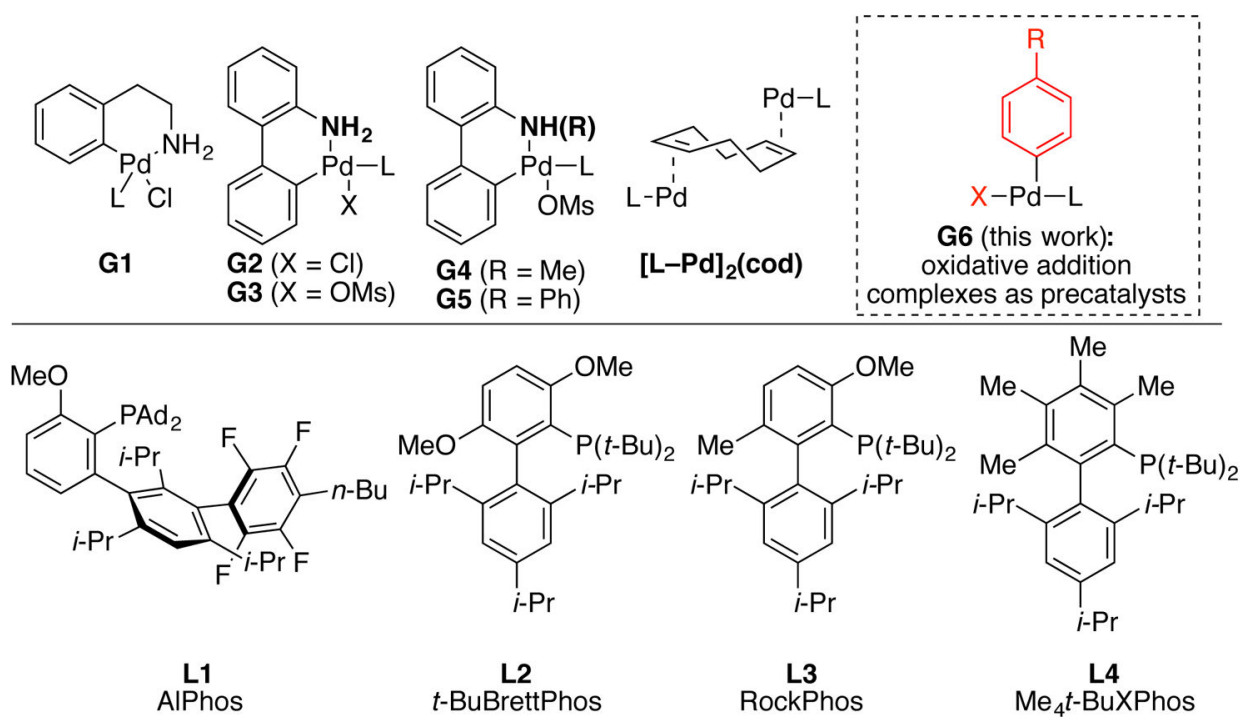

Figure 1.

Evolution of precatalysts developed by the Buchwald group and selected bulky supporting ligands. 


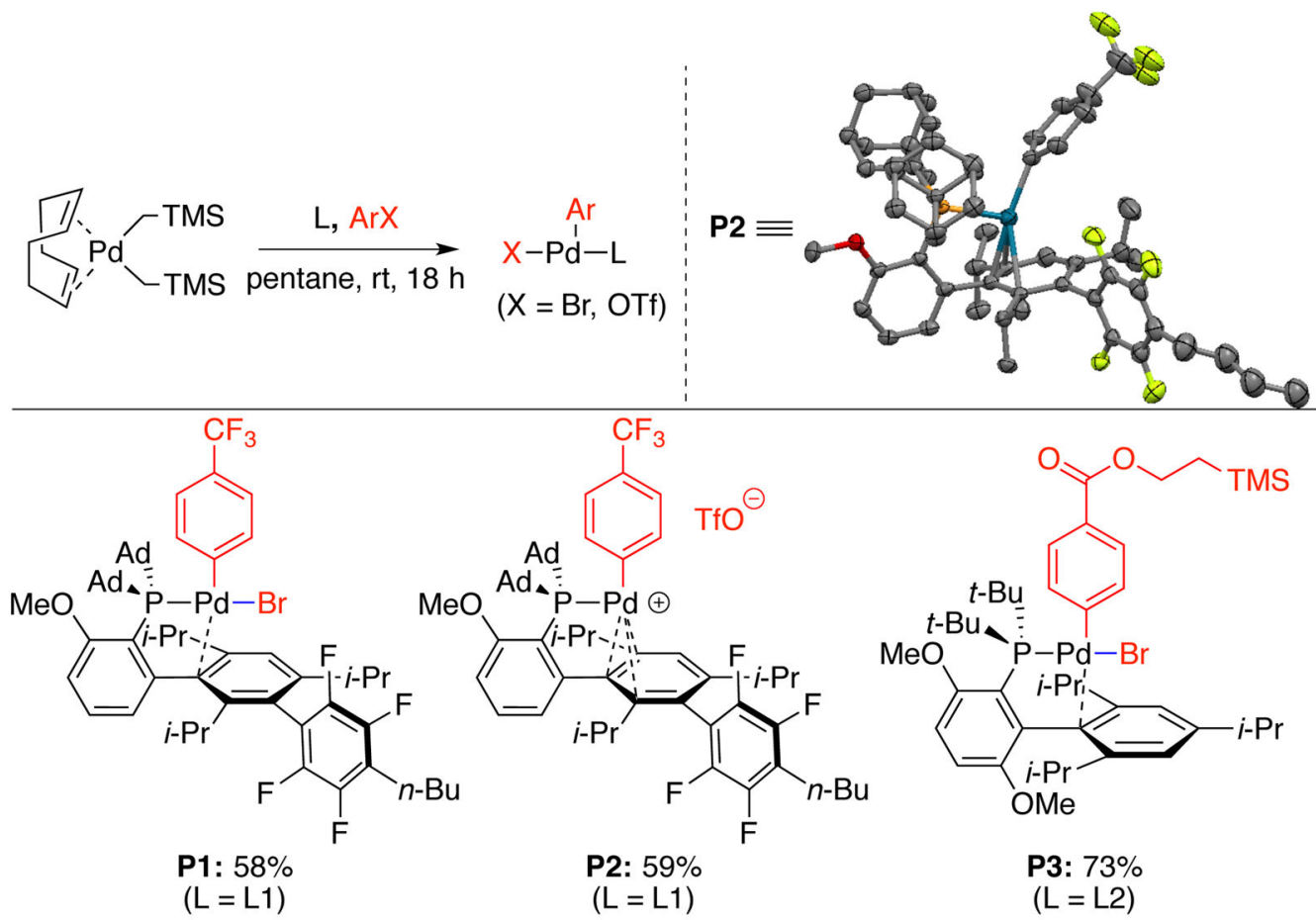

Scheme 1. Synthesis of Oxidative Addition Complexes

Structures of OACs used as precatalysts. Crystallographically determined X-ray structure of P2 shown (thermal ellipsoid plot at 50\% probability, triflate anion and hydrogen atoms, are omitted). 

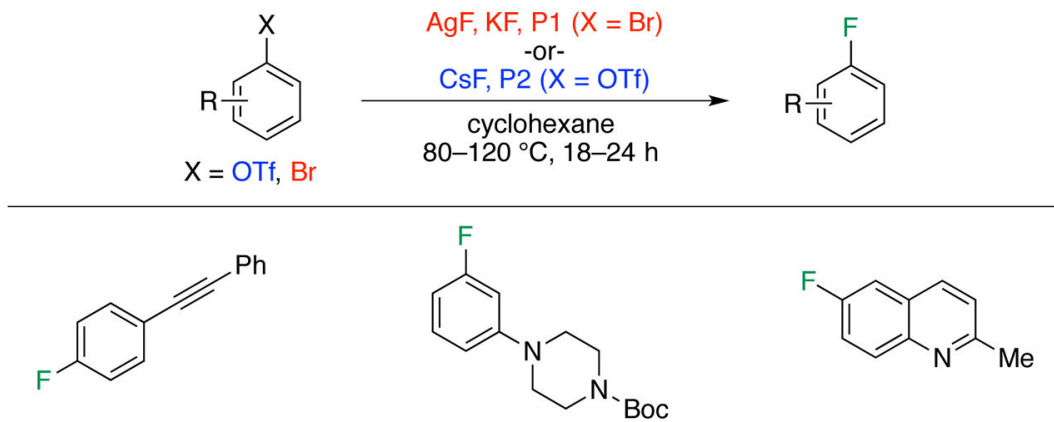

$2 a$

$4 \% \mathrm{Pd}, 2 \% \operatorname{cod}$

$80^{\circ} \mathrm{C}, 24 \mathrm{~h}$

$(\mathrm{X}=\mathrm{Br}$ )

$90 \%$

$4 \%$ Pd, $2 \%$ cod

$120^{\circ} \mathrm{C}, 18 \mathrm{~h}$

$(\mathrm{X}=\mathrm{Br})$
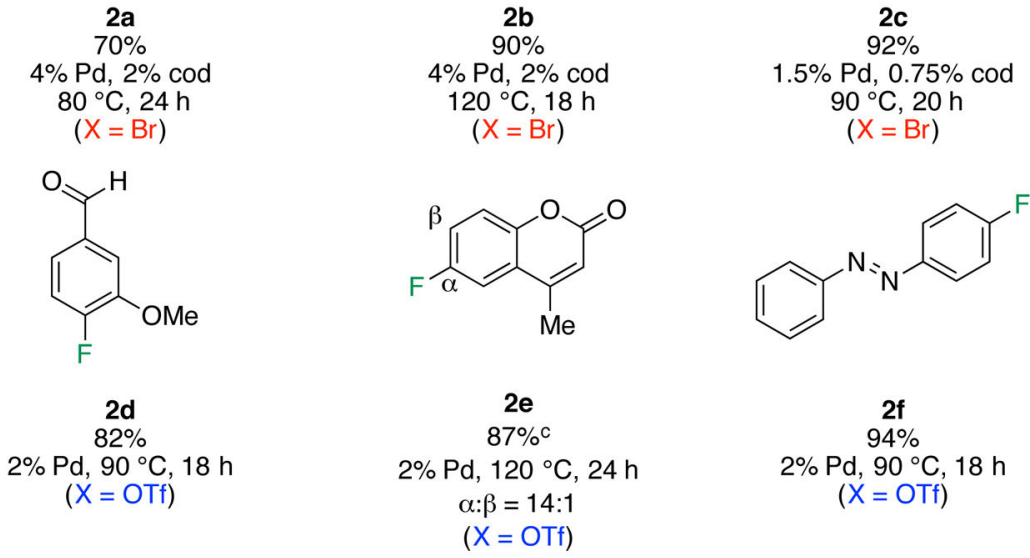

( $\mathrm{X}=\mathrm{OTf}$ )

Scheme 2. Fluorination of aryl bromides and triflates with $P 1$ and $P 2^{a, b}$

assolated yields are reported as an average of two runs. General conditions: $\mathrm{ArBr}(1.0$ $\mathrm{mmol}), \operatorname{AgF}(2.0 \mathrm{mmol}), \mathrm{KF}(0.5 \mathrm{mmol})$, cyclohexane $(10 \mathrm{~mL}) .{ }^{\mathrm{b}}$ ArOTf $(1.0 \mathrm{mmol}), \mathrm{CsF}$ $(3.0 \mathrm{mmol})$, cyclohexane $(10 \mathrm{~mL}){ }^{\mathrm{c}}$ Toluene was the reaction solvent. 


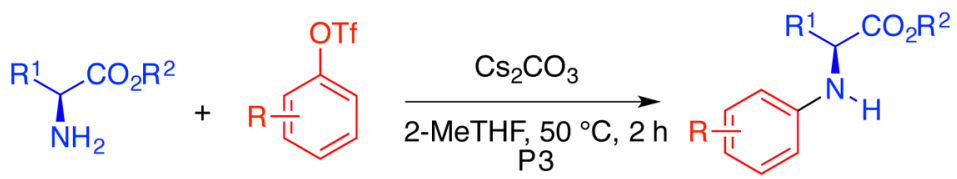<smiles>Cc1cc(Cl)ccc1NC(Cc1ccccc1)C(=O)OCc1ccccc1</smiles><smiles>CCOC(=O)c1cccc(NC(Cc2ccccc2)C(=O)OC(C)(C)C)c1</smiles><smiles>CC(=O)OCCNNC(=O)OCc1ccccc1Nc1cnc2ccccc2c1</smiles><smiles>CC(=O)NCCC(Nc1ccc(-n2cccc2)cc1)C(C)=O</smiles>

Scheme 3. Amino Acid Ester Arylation with $\mathbf{P 3}^{\mathbf{a}, \mathrm{b}}$

a Isolated yields are reported as an average of two runs. General conditions: ArOTf (1.0 $\mathrm{mmol}$ ), amino acid ester (1.1 mmol), $\mathrm{Cs}_{2} \mathrm{CO}_{3}(3.0 \mathrm{mmol}), \mathbf{P 3}(5 \mathrm{~mol} \%), 2$ methyltetrahydrofuran $(2 \mathrm{~mL})$. ${ }^{\mathrm{b}}$ Enantiomeric excess (ee, average of two runs) was determined by HPLC analysis using chiral stationary phases. 

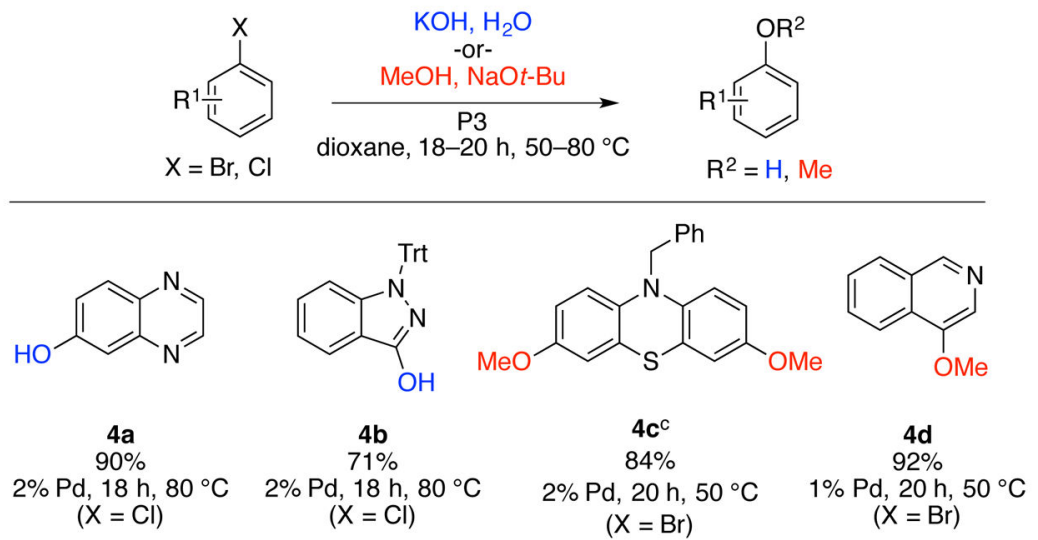

Scheme 4. Alcohol and Hydroxide Coupling with P3 ${ }^{\mathrm{a}}$

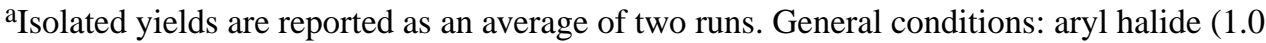
mmol), $\mathrm{KOH}$ (3.0 mmol), $\mathrm{H}_{2} \mathrm{O}$ (20 mmol), 1,4-dioxane (2 mL). ${ }^{\mathrm{b}}$ Aryl halide (1.0 mmol), $\mathrm{MeOH}$ (5 mmol), $\mathrm{NaO} t-\mathrm{Bu}(1.2 \mathrm{mmol}), 1,4$-dioxane $(2 \mathrm{~mL}) .{ }^{\mathrm{c}} 2.4$ equivalents of $\mathrm{NaO} t-\mathrm{Bu}$ and 10 equivalents of $\mathrm{MeOH}$. 


\section{Table 1}

Additive effects on the fluorination of 1-bromo-4-n-butylbenzene with $\mathbf{P 1}$ as precatalyst. ${ }^{a}$

\begin{tabular}{|c|c|c|c|}
\hline$\underbrace{\mathrm{Bru}}_{(0.1 \mathrm{mmol})}$ & $\begin{array}{c}\mathrm{AgF}(2.0 \text { equiv }) \\
\mathrm{KF}(0.5 \text { equiv }) \\
4 \%[\mathrm{Pd}] \\
\mathrm{cy}, 90^{\circ} \mathrm{C}, 24 \mathrm{~h}\end{array}$ & $\begin{array}{c}n-\mathrm{Bu} \\
\mathbf{A}\end{array}$ & B-Bu \\
\hline entry & [Pd] & additive & yield A (B) \\
\hline 1 & {$[\mathbf{L 1}-\mathrm{Pd}]_{2}(\mathrm{cod})$} & - & $87 \%(5 \%)$ \\
\hline 2 & P1 & - & $22 \%(1 \%)$ \\
\hline 3 & P1 & $2 \% \operatorname{cod}$ & $91 \%(6 \%)$ \\
\hline
\end{tabular}

${ }^{a}$ Yields reported as ${ }^{19} \mathrm{~F}$ NMR yields using 1-fluoronaphthalene as an internal standard. cy = cyclohexane. cod = 1,5-cyclooctadiene. 